\title{
BMJ Open A randomised controlled trial for the evaluation of risk for type 2 diabetes in hypertensive patients receiving thiazide diuretics: Diuretics In the Management of Essential hypertension (DIME) study
}

\author{
Shinichiro Ueda, ${ }^{1}$ Takeshi Morimoto, ${ }^{2}$ Shin-ichi Ando, ${ }^{3,4}$ Shu-ichi Takishita, ${ }^{5}$ \\ Yuhei Kawano, ${ }^{6}$ Kazuaki Shimamoto, ${ }^{7}$ Toshio Ogihara, ${ }^{8}$ Takao Saruta, ${ }^{9}$ \\ for the DIME Investigators
}

To cite: Ueda S, Morimoto T, Ando $\mathrm{S}$, et al. A randomised controlled trial for the evaluation of risk for type 2 diabetes in hypertensive patients receiving thiazide diuretics: Diuretics In the Management of Essential hypertension (DIME) study. BMJ Open 2014;4:e004576. doi:10.1136/bmjopen-2013004576

- Prepublication history and additional material is available. To view please visit the journal (http://dx.doi.org/ 10.1136/bmjopen-2013004576).

Received 29 November 2013 Revised 7 June 2014 Accepted 13 June 2014

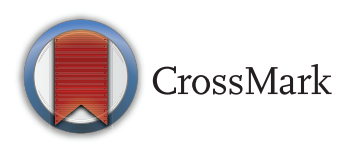

For numbered affiliations see end of article.

Correspondence to Dr Shinichiro Ueda; blessyou@med.u-ryukyu.ac.jp

\section{ABSTRACT}

Objectives: Thiazide diuretics are one of the first choice antihypertensives but not optimally utilised because of concerns regarding their adverse effects on glucose metabolism. The Diuretics In the Management of Essential hypertension (DIME) study was designed, for the first time, to assess the risk for type 2 diabetes mellitus in patients with essential hypertension during antihypertensive treatment with low-dose thiazide diuretics compared to those not treated with diuretics. Design: Multicentre, unblinded, pragmatic, randomised, controlled trial with blinded assessment of end points and intention-to-treat analysis that was started in 2004 and finished in 2012.

Setting: Hypertension clinics at 106 sites in Japan, including general practitioners' offices and teaching hospitals.

Participants: Non-diabetic patients with essential hypertension.

Interventions: Antihypertensive treatment with lowdose thiazide diuretics at $12.5 \mathrm{mg} / \mathrm{day}$ of hydrochlorothiazide or equivalent (Diuretics group) or that without thiazide diuretics (No-diuretics group).

Main outcome: The primary outcome was new onset of type 2 diabetes diagnosed according to WHO criteria and the criteria of Japanese Society of Diabetes.

Results: 1130 patients were allocated to Diuretics $(n=544)$ or No-diuretics group $(n=586)$. Complete end point information was collected for 1049 participants after a median follow-up of 4.4 years. Diabetes developed in $25(4.6 \%)$ participants in the Diuretics group, as compared with $29(4.9 \%)$ in the No-diuretics group (HR 0.93; 95\% Cl 0.55 to 1.58; $p=0.800$ ).

Conclusions: Antihypertensive treatment with thiazide diuretics at low doses may not be associated with an increased risk for new onset of type 2 diabetes. This result might suggest safety of use of low doses of thiazide diuretics.

Trial registration number: ClinicalTrials.gov NCT00131846.

\section{Strengths and limitations of this study}

- This is one of very few randomised controlled trials that assessed effects of low dose thiazide diuretics on risk for type 2 diabetes.

- The main strengths of our trial are that our results might suggest safety of antihypertensive treatment with low dose thiazide diuretics.

- The limitation of our study is insufficient statistical power for equivalency of the primary endpoint.

\section{INTRODUCTION}

Antihypertensive treatment with thiazide diuretics effectively reduces cardiovascular risk in hypertensive patients ${ }^{1-4}$ and there has been evidence to suggest no inferiority when compared to 'newer' antihypertensive drugs. ${ }^{5}$ However, concern remains regarding adverse effects of diuretics on glucose metabolism and the prognostic implications of such effects on cardiovascular events. ${ }^{6} 7$

The diabetogenic effect of diuretics seems to be taken for granted. In fact, in addition to results from a large cohort study, ${ }^{8}$ a recent network meta-analysis conclusively showed a higher risk for new onset of type 2 diabetes in patients receiving thiazide diuretics than in those receiving calcium antagonists, ACE inhibitors, angiotensin receptor blockers (ARB) or placebo. ${ }^{9}$ It is of note, however, that relatively high doses of thiazide diuretics (25 mg of hydrochlorothiazide equivalent or more) were used mainly with $\beta$-blockers in most studies included in this meta-analysis. Antihypertensive treatment with diuretics in this way is no longer relevant to current antihypertensive therapeutic practice. Thiazide 
diuretics are currently used at relatively low doses, more likely in combination with inhibitors of the renin-angiotensin system (RAS) and calcium antagonists, according to the clinical background of the patient, rather than as a single agent with dose titration. Therefore, there is a need for assessment of the metabolic effects of treatment with low-dose diuretics rather than of those of diuretics per se. In addition, from the methodological point of view, as no study thus far has assessed the diabetogenic effect of diuretics as the primary end point, this study is being done to fill that gap.

Although there is no universal agreement that thiazide diuretics are the first-choice antihypertensive drug, evidence from clinical trials in 'salt sensitive' patients, such as ALLHAT (Antihypertensive and Lipid-Lowering Treatment to Prevent Heart Attack Trial), ${ }^{5}$ and pathophysiological considerations regarding salt intake and blood pressure control, suggest that appropriate use of thiazide diuretics is undoubtedly necessary for a large subpopulation of hypertensive patients.

This study of Japanese patients with essential hypertension was performed to assess the hypothesis that antihypertensive treatment with low-dose thiazide diuretics may not be associated with a higher risk for new onset of type 2 diabetes and other metabolic abnormalities compared to treatment of such patients without diuretics.

\section{METHODS}

\section{Trial design}

This was an independent, investigator-initiated, multicentre, pragmatic, randomised, open, blinded-end point, parallel group study conducted in Japan (NCT00131846).

\section{Study setting}

This study was conducted in Japan at hypertension clinics of 106 sites including general practitioners' offices $(n=61)$ and teaching hospitals $(n=45)$. All members of committees for this Diuretics In the Management of Essential hypertension (DIME) study and the DIME investigators who participated in the study settings, data collection and management are listed in the online supplementary appendix.

\section{Participant}

Patients were eligible if they were aged $30-79$ years at randomisation, and had either untreated hypertension with systolic blood pressure of $150 \mathrm{~mm} \mathrm{Hg}$ or more, diastolic blood pressure of $90 \mathrm{~mm} \mathrm{Hg}$ or more, or both; or treated hypertension with systolic blood pressure of $140 \mathrm{~mm} \mathrm{Hg}$ or more, diastolic blood pressure $90 \mathrm{~mm} \mathrm{Hg}$ or more, or both. Patients were excluded if they had type 2 diabetes, gout, systolic blood pressure of $200 \mathrm{~mm} \mathrm{Hg}$ or more, diastolic blood pressure of $120 \mathrm{~mm} \mathrm{Hg}$ or more, hypokalaemia $(<3.5 \mathrm{mmol} / \mathrm{L})$, erectile dysfunction, renal dysfunction (serum creatinine levels of $2.0 \mathrm{mg} / \mathrm{dL}$ or more), history of stroke or myocardial infarction within 3 months, history of revascularisation of coronary arteries within 6 months, heart failure or left ventricular dysfunction (ejection fraction $<40 \%$ ), history of serious adverse reaction to thiazide diuretics, or history of malignant tumour within 5 years. Patients who were pregnant, breastfeeding, already on thiazide treatment or on any antihypertensive treatment if the duration of treatment and drugs used were not identified, and those deemed not eligible for this study for any other reason, were also excluded.

\section{Assignment to study treatment}

Eligible patients were randomly assigned to receive thiazide diuretics at a low dose that was defined as $12.5 \mathrm{mg}$ / day of hydrochlorothiazide, $1 \mathrm{mg} /$ day of indapamide or $1 \mathrm{mg} /$ day of trichloromethiazide along with any other antihypertensive drugs as required to achieve target blood pressure $(<140 /<90 \mathrm{~mm} \mathrm{Hg})$ (Diuretics group) or receive any antihypertensive drugs other than thiazide diuretics to achieve target blood pressure $(<140 /$ $<90 \mathrm{~mm} \mathrm{Hg}$ ) (No-diuretics group) by minimisation method $^{10}{ }^{11}$ with assignment factors being impaired fasting glycaemia (fasting blood glucose $\geq 110 \mathrm{mg} / \mathrm{dL}$ or $<110 \mathrm{mg} / \mathrm{dL}$ ), family history of type 2 diabetes mellitus and body mass index $\left(\geq 25\right.$ or $\left.<25 \mathrm{~kg} / \mathrm{m}^{2}\right)$ and region of trial sites.

\section{Concealment of assignment}

We developed a web-based minimisation system that was controlled by the data centre and effectively concealed the assignment sequence from investigators assessing and recruiting patients.

\section{Follow-up schedule}

Patients regularly visited their outpatient clinic monthly or bimonthly. Sitting blood pressure, heart rate and plasma concentrations of fasting glucose, creatinine, uric acid, potassium and sodium were measured and recorded every 6 months. Glycated haemoglobin (HbAlc) and lipid profiles were measured yearly.

\section{End points and outcome measure}

The primary end point of DIME study was new onset of type 2 diabetes mellitus. The secondary end points were all-cause mortality, ischaemic and haemorrhagic strokes excluding transient ischaemic attacks and secondary causes, myocardial infarction, hospitalisation due to heart failure, gout, treatment-resistant hypokalaemia and peripheral artery disease including arteriosclerosis obliterans (ASO), aortic aneurysm, blood pressure, lipid profiles, HbA1c, fasting blood glucose and direct cost.

Investigators submitted all information relevant to any of the potential end points to the data centre for review by the end point committee, who were blinded to the treatment assignment. We collected data continuously even after patients suffered a non-fatal secondary end point in order to assess whether onset of diabetes 
occurs. Diagnostic criteria for each end point were defined a priori and were used by the end point committee. Briefly, diagnosis of the primary end point was made according to WHO criteria $1998^{12}$ and the criteria of the Japanese Diabetes Society ${ }^{13}$ based on the results from regular assessment of blood glucose. Gout was diagnosed according to the American College of Rheumatology 1977 criteria C. ${ }^{14}$ Treatment-resistant hypokalaemia was defined as continuous hypokalaemia $(<3.5 \mathrm{mmol} / \mathrm{L})$ even after the addition of potassiumsparing drugs or potassium supplementation in patients without any evidence of secondary hypertension. Diagnosis of stroke, myocardial infarction or heart failure was made by WHO MONICA Project diagnostic criteria, ${ }^{15}$ AHA Scientific Statement $2003^{16}$ or diagnostic criteria of the Framingham study, ${ }^{17}$ respectively. Renal dysfunction was defined as doubling of serum creatinine concentrations, of $4 \mathrm{mg} / \mathrm{dL}$ or more, or progression to end-stage renal disease (renal transplantation or haemodialysis). Dissection of aortic aneurysm was diagnosed by medical history, symptoms and imaging. Deterioration of ASO was defined according to the Fontaine classification. $^{18}$

\section{Statistical analyses}

\section{Sample size}

The trial was designed as an equivalence trial, which was powered for equivalence of Diuretics to No-diuretics group on the primary end point. With the assumption of $5.5 \%$ of occurrence of type 2 diabetes among Diuretics and No-diuretics groups for 4 years based on the previous reports, ${ }^{19} 20955$ patients per group would yield $90 \%$ power to detect equivalence with an equivalence margin of $3 \%$ at a level of two-sided type 1 error of 0.05 in one group. We also calculated that 713 patients per group would yield $80 \%$ power. Thus, a total of 2400 and 1800 patients as the total sample size were to be enrolled, accommodating a possible $20 \%$ dropout during the follow-up period, in order to provide $90 \%$ and $80 \%$ power, respectively.

\section{Evaluation of effects of antihypertensive treatment with low-dose thiazide diuretics}

Continuous variables were expressed as mean $\pm \mathrm{SD}$ or median with IQR. Continuous variables were compared using the Student t test or Wilcoxon rank-sum test based on their distributions. Clinical outcomes were analysed according to the intention-to-treat principle. Each end point was assessed by the Kaplan-Meier method and compared by the log-rank test. Time-to-events analysis of the primary end point should be justified because of regular assessment of glucose with short intervals. Effect of treatment was compared by the Cox proportional hazard model, and was expressed by HR with 95\% CI. Comparison was also made with the adjustment by assignment factors. As a sensitivity analysis, we compared incidence of diabetes diagnosed by WHO criteria only between the groups. Treatment effect was evaluated in several prespecified subgroups, including stratified variables, concomitant antihypertensives and dose of diuretics as a subgroup analysis. In addition, we also performed on-treatment analysis to assure results from intention-to treat analysis. No-diuretics group was defined as patients receiving no diuretics throughout the study period and diuretics group was defined as patients receiving diuretics at the end of the observation period irrespective of allocated treatment. The study statistician conducted all statistical analyses with the use of JMP V.8.0 and SAS V.9.3 (SAS Institute Inc, Cary, North Carolina, USA). All reported $\mathrm{p}$ values were two-sided with the significance level set at $\alpha=0.05$.

\section{RESULTS}

The recruitment of patients was started on 5 April 2004 and terminated on 7 February 2012 despite insufficient statistical power at that point because the steering committee thought that further extension would not promote the enrolment of patients. The follow-up was then terminated at the end of August 2012. We did not conduct interim analyses because of insufficient enrolment of patients. 1130 patients were randomised (figure 1). Randomised patients were similar between groups with regard to demographic and clinical characteristics (table 1). Complete end point information was collected at the end of the study for 1049 (92.9\%) participants after a median follow-up of 4.4 years (figure 1). Twenty-five (2.2\%) patients withdrew consent and $56(4.9 \%)$ were lost to follow-up. At the end of follow-up, $75 \%$ of participants randomly assigned to Diuretic group were still taking thiazide diuretics and $6 \%$ of participants assigned to No-diuretics group were taking thiazide diuretics. Approximately 80\% of patients received RAS inhibitors and approximately $20 \%$ of them received $\beta$-blockers in Diuretics and No-diuretics groups at the end of follow-up period (table 2).

\section{The primary end point and glucose-related outcome}

The primary end point of new onset of type 2 diabetes did not differ significantly between the groups (figure 2). During the study, diabetes developed in $25(4.6 \%)$ participants in the Diuretics group, as compared with 29 (4.9\%) in the No-diuretics group (HR $0.93 ; 95 \%$ CI 0.54 to 1.59 ; log-rank test: $\mathrm{p}=0.800$ ). Actual statistical power became $60 \%$. Comparison by the Cox proportional hazard model with the adjustment by assignment variables showed similar results (HR 0.91; 95\% CI 0.53 to $1.58 ; \mathrm{p}=0.741)$. The incidence of diabetes was 19 in No-diuretics and 19 in Diuretics groups when diagnosed according to WHO criteria only. There was no significant difference between the groups (HR 1.07, 95\% CI 0.56 to $2.03, \mathrm{p}=0.8438$ ). Although statistically underpowered, subgroup analysis did not identify any factors interacting with effects of use of diuretics on development of diabetes (figure 3). On treatment analysis there was no significant difference in incidence of type 2 diabetes 
Figure 1 Enrolment, randomisation and follow-up of study participants.

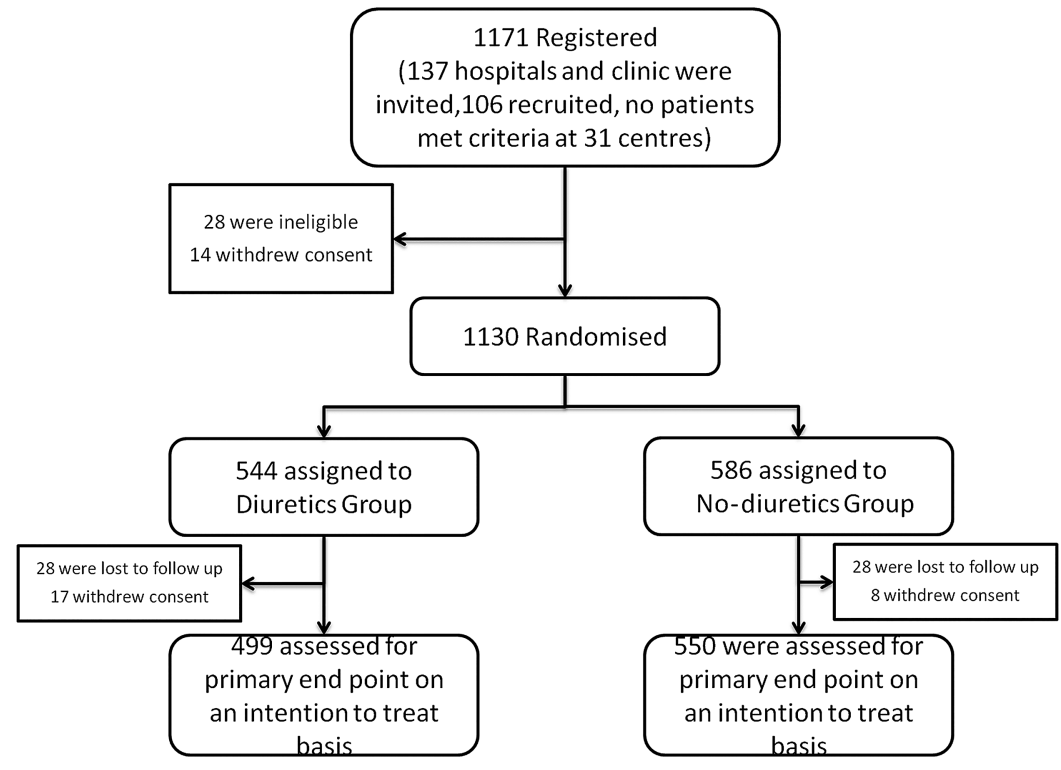

between No-diuretics and Diuretics groups (HR 1.21; $95 \%$ CI 0.70 to $2.06 ; \mathrm{p}=0.489$ ).

Averaged fasting plasma glucose concentrations and HbA1c levels overtime and at the end of follow-up period are shown in figure 4 and table 3, respectively. Levels of fasting glucose or HbAlc in the Diuretics group throughout the study were not significantly higher than those in the No-diuretics group.
Secondary end points

There were no apparent differences between the groups in measured secondary end point including gout, treatment resistant hypokalaemia, death and cardiovascular events (table 4). Averaged serum potassium concentrations overtime and at the end of follow-up period were shown in figure $5 \mathrm{~A}$ and table 3 , respectively. At $0.5,1$, $1.5,2$ and 2.5 years and at the end of follow-up period,

Table 1 Baseline characteristics of participants

\begin{tabular}{|c|c|c|}
\hline & Diuretics group $(n=544)$ & No-diuretics group $(n=586)$ \\
\hline Men (\%) & $269(49.4)$ & $281(48.0)$ \\
\hline Age (years) & $63(10)$ & $63(10)$ \\
\hline Body weight (kg) & $62(12)$ & $63(12)$ \\
\hline Body mass index $\left(\mathrm{kg} / \mathrm{m}^{2}\right)$ & $24.6(3.5)$ & $25.3(4.1)$ \\
\hline On drug treatment $(\%)$ & $461(84.7)$ & 507 (86.5) \\
\hline Positive family history of type 2 diabetes (\%) & $88(16.1)$ & $78(13.2)$ \\
\hline History of stroke $(\%)$ & $11(1.9)$ & $20(3.4)$ \\
\hline History of myocardial infarction (\%) & $10(1.8)$ & $11(1.9)$ \\
\hline History of peripheral arterial disease (\%) & $2(0.4)$ & $5(0.9)$ \\
\hline Left ventricular hypertrophy (\%) & $73(13.4)$ & $61(10.4)$ \\
\hline Alcohol intake (+) (\%) & $256(47.1)$ & $267(45.6)$ \\
\hline Current smoker (\%) & $84(15.4)$ & $86(14.7)$ \\
\hline Systolic BP (mm Hg) & $154(11)$ & $154(10)$ \\
\hline Diastolic BP (mm Hg) & $88(10)$ & $88(10)$ \\
\hline Pulse rate (bpm) & $74(11)$ & $75(11)$ \\
\hline Fasting plasma glucose (mg/dL) & $99(11)$ & $100(10)$ \\
\hline $\mathrm{HbA1c}(\%)$ & $5.3(0.4)$ & $5.3(0.4)$ \\
\hline Uric acid (mg/dL) & $5.5(1.3)$ & $5.6(1.2)$ \\
\hline $\mathrm{K}(\mathrm{mmol} / \mathrm{L})$ & $4.2(0.4)$ & $4.2(0.4)$ \\
\hline $\mathrm{Na}(\mathrm{mmol} / \mathrm{L})$ & $141(2)$ & $141(3)$ \\
\hline eGFR $\left(\mathrm{mL} / \mathrm{min} / 1.73 \mathrm{~m}^{2}\right)$ & $73.7(15.5)$ & $74.0(16.0)$ \\
\hline Total cholesterol (mg/dL) & $207(32)$ & $204(33)$ \\
\hline HDL cholesterol (mg/dL) & $60(18)$ & $59(17)$ \\
\hline Triglyceride (mg/dL) & $137(94)$ & $136(84)$ \\
\hline
\end{tabular}


Table 2 Concurrent drug treatment at the baseline and the end of follow-up

\begin{tabular}{|c|c|c|c|c|}
\hline & \multicolumn{2}{|c|}{ At the baseline after randomisation } & \multicolumn{2}{|c|}{ At the end of follow-up } \\
\hline & $\begin{array}{l}\text { Diuretics group } \\
(n=544)\end{array}$ & $\begin{array}{l}\text { No-diuretics group } \\
(n=586)\end{array}$ & $\begin{array}{l}\text { Diuretics group } \\
(n=504)\end{array}$ & $\begin{array}{l}\text { No-diuretics group } \\
(\mathrm{n}=565)\end{array}$ \\
\hline Thiazide diuretics & $518(98.9)$ & $0(0)$ & $379(75.2)$ & $32(5.7)$ \\
\hline ACE inhibitors & $53(10.1)$ & $86(14.9)$ & 42 (8.3) & $70(12.4)$ \\
\hline ARB & $292(55.7)$ & $388(67.0)$ & 349 (69.3) & $377(66.7)$ \\
\hline Ca antagonist & $284(54.2)$ & $437(75.5)$ & $313(62.1)$ & $436(77.2)$ \\
\hline$\beta$-blocker & 99 (18.9) & $132(22.8)$ & $107(21)$ & $132(23)$ \\
\hline$\alpha$-blocker & $12(2.3)$ & $34(5.9)$ & $18(3.6)$ & $30(5.3)$ \\
\hline Anti-aldosterone & $6(1.2)$ & $13(2.3)$ & $23(4.6)$ & $31(5.5)$ \\
\hline Others & $1(0.2)$ & $1(0.2)$ & $2(0.4)$ & $4(0.7)$ \\
\hline Statins & $140(26.7)$ & $141(24.4)$ & $188(37.3)$ & $211(37.4)$ \\
\hline Antiplatelet & 80 (15.3) & 73 (12.6) & 87 (17.3) & $82(14.5)$ \\
\hline K supplement & $0(0)$ & $0(0)$ & $1(0.2)$ & $2(0.4)$ \\
\hline $\begin{array}{l}\text { Drugs for } \\
\text { hyperuricaemia }\end{array}$ & $34(6.5)$ & $36(6.2)$ & $58(11.5)$ & $51(9.0)$ \\
\hline
\end{tabular}

serum potassium levels were very slightly but significantly lower by $0.1 \mathrm{mmol} / \mathrm{L}$ in the Diuretics group than those in the No-diuretics group. Serum sodium levels at the end of follow-up period were also slightly but significantly lower by $<1 \mathrm{mmol} / \mathrm{L}$ in the Diuretics group than those in No-diuretics group (table 3). Averaged serum uric acid concentrations overtime and at the end of follow-up period were shown in figure $5 \mathrm{~B}$ and table 3 , respectively. From 0.5 to 4.5 years during the study period and at the end of follow-up period, serum uric acid levels were significantly higher in the Diuretics group than those in the No-diuretics group. There were no significant differences in estimated glomerular filtration rate and lipid profile between the groups (table 3).

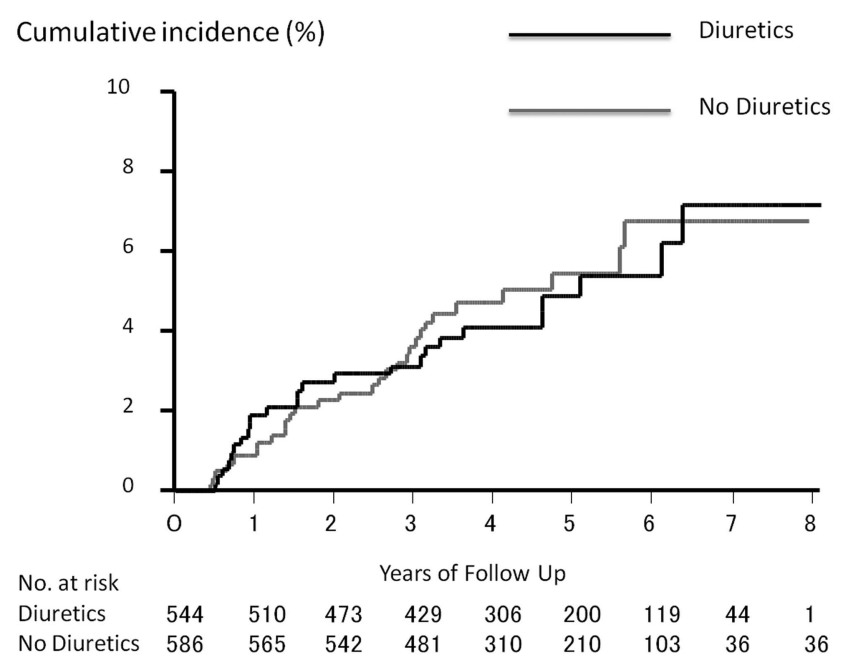

Figure 2 Kaplan-Meier curves of cumulative incidence of type 2 diabetes.

\section{Blood pressure}

There was no significant difference in blood pressure between the groups during the study or at the end of follow-up period (figure 6 and table 3 ).

\section{DISCUSSION}

We demonstrate that the incidence of type 2 diabetes was not higher in our Japanese patients with essential hypertension receiving antihypertensive treatment with low-dose thiazide diuretics compared to those treated without diuretics although statistically underpowered for equivalency. Consistency between intention-to-treat analysis and on-treatment analysis might assure our conclusion. A lack of adverse effects of low-dose diuretics on glucose metabolism, represented by fasting glucose levels and HbAlc (which were consistent with the incidence of diabetes), was also demonstrated.

Unlike our results, a recent meta-analysis of 22 clinical trials showed that diuretics use was associated with a greater risk of new onset of diabetes compared to other antihypertensive drugs and placebo in hypertensive patients. ${ }^{6}$ We assume that differences in the dose of diuretics used, concurrent antihypertensive drugs used with diuretics and the study design may explain different results regarding incidence of diabetes. Doses of thiazide diuretics in most studies included in the meta-analysis by Elliot and Meyer were higher (25 mg of hydrochlorothiazide or more) than those used in the current study. Similarly, although Bakris et $a l^{21}$ showed that the fixed combination of losartan and hydrochlorothiazide impaired glucose tolerance in hypertensive patients with metabolic syndrome, the dose of this combination was titrated to $100 \mathrm{mg}$ of losartan and $25 \mathrm{mg}$ of hydrochlorothiazide in approximately $80 \%$ of patients. As Carlsen et $a l^{22}$ showed previously, there is a clear relationship between dose of thiazide diuretics and effect on glucose, 


$\begin{array}{llll} & \text { Diuretics } & \text { Non diuretics } & \\ & \text { Number (\%) } & \text { Number (\%) } & \text { Unadjusted } \mathrm{HR} \\ \text { All patients } & 25(4.6 \%) & 29(4.9 \%) & 0.93(0.54-1.59) \\ \text { Male } & 17(6.3 \%) & 17(6.0 \%) & 1.08(0.55-2.12) \\ \text { Female } & 8(2.9 \%) & 12(3.9 \%) & 0.71(0.28-1.73) \\ \text { Family history of diabetes (+) } & 8(9.1 \%) & 6(7.7 \%) & 1.14(0.39-3.47) \\ \text { Family history of diabetes (-) } & 17(3.7 \%) & 23(4.5 \%) & 0.83(0.43-1.54) \\ \text { FBS >=100 mg/dl } & 16(17.0 \%) & 14(12.4 \%) & 1.32(0.64-2.75) \\ \text { FBS<100 mg/dl } & 9(2.0 \%) & 15(3.2 \%) & 0.64(0.27-1.44) \\ \text { Age >= 65 years old } & 10(3.4 \%) & 13(4.2 \%) & 0.77(0.33-1.75) \\ \text { Age <65 years old } & 15(6.0 \%) & 16(5.7 \%) & 1.08(0.53-2.20) \\ \text { BMI >=25Kg/m } & 17(7.4 \%) & 19(6.6 \%) & 1.10(0.57-2.12) \\ \text { BMI <25Kg/m } & 8(2.5 \%) & 10(3.3 \%) & 0.79(0.30-2.00) \\ \text { With Beta Blocker } & 5(5.1 \%) & 6(4.5 \%) & 1.13(0.32-3.74) \\ \text { Without Beta Blocker } & 20(4.7 \%) & 23(5.1 \%) & 0.90(0.49-1.64) \\ \text { With ACEI/ARB } & 19(5.6 \%) & 23(5.1 \%) & 1.13(0.61-2.07) \\ \text { Without ACEI/ARB } & 6(3.2 \%) & 6(4.8 \%) & 0.62(0.20-2.00) \\ & & & 0.1\end{array}$

Figure 3 Effects of diuretics use on risk of new onset of diabetes according to the baseline characteristics. FBS, fasting blood sugar; BMI, body mass index; ACEI/ARB, ACE inhibitor or angiotensin receptor blocker.

potassium and uric acid but not blood pressure. Results from our study suggest that treatment with diuretics at the dose of $12.5 \mathrm{mg}$ of hydrochlorothiazide equivalent may not increase the risk for new onset of diabetes; that is, the diabetogenic effect of thiazide diuretics may also be dose dependent. One might claim that there is no evidence to support that diuretics at the doses used in this study reduce cardiovascular events. However, improved cardiovascular outcome can be expected as long as target blood pressure is achieved by a combination of drugs including thiazide diuretics even at low doses (12.5 mg of hydrochlorothiazide or equivalent).
Figure 4 Plasma fasting glucose $(A)$ and glycated hemoglobin $(B)$ over time by groups.
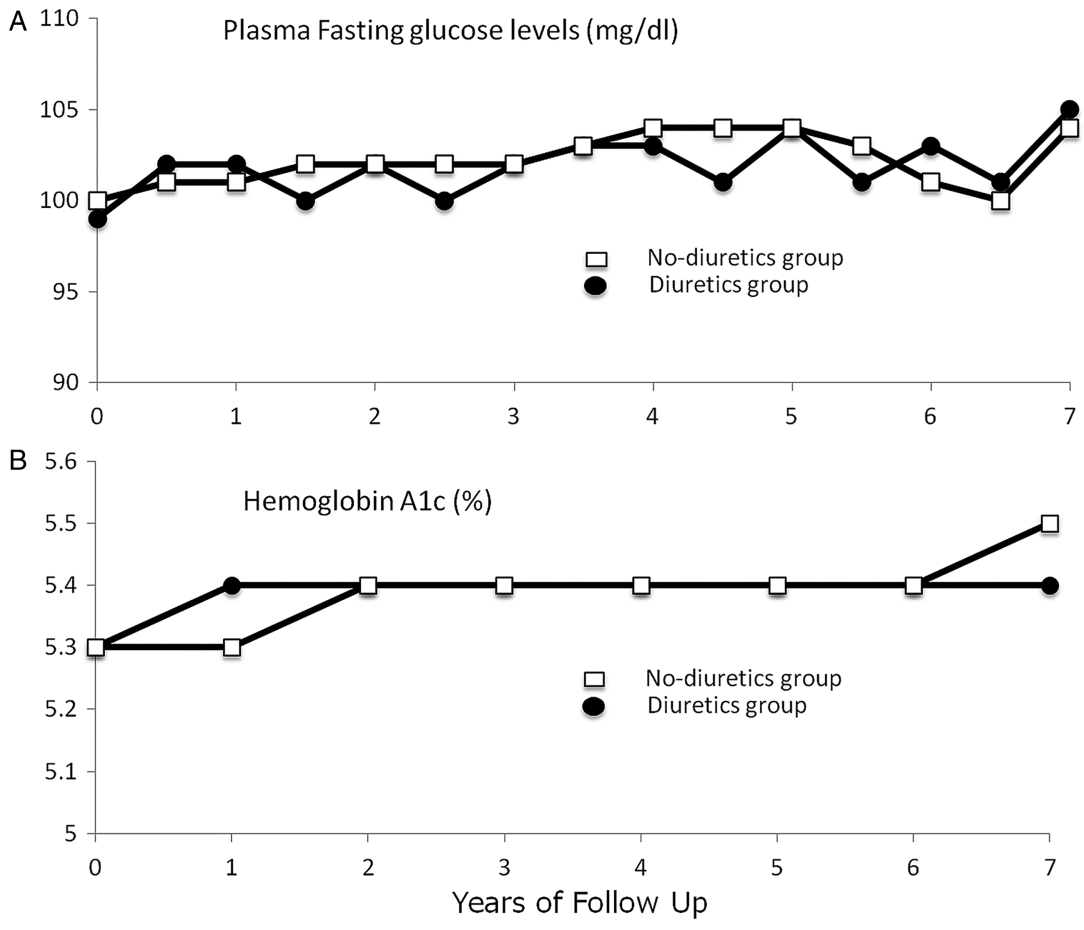
Table 3 Blood pressure, glucose, uric acid, electrolytes, renal function and lipid profile at the end of follow-up

\begin{tabular}{lccc}
\hline & Diuretics group $(\mathbf{n = 5 4 4 )}$ & No-diuretics group $(\mathbf{n = 5 8 6})$ & $\mathbf{p}$ Value \\
\hline Systolic BP $(\mathrm{mm} \mathrm{Hg})$ & $135(16)$ & $135(15)$ & 0.900 \\
Diastolic BP $(\mathrm{mm} \mathrm{Hg})$ & $78(11)$ & $77(11)$ & 0.800 \\
Pulse rate $(\mathrm{bpm})$ & $73(11)$ & $73(11)$ & 0.998 \\
Fasting glucose $(\mathrm{mg} / \mathrm{dL})$ & $102(14)$ & $103(16)$ & 0.423 \\
HbA1c $(\%)$ & $5.4(0.4)$ & $5.4(0.4)$ & 0.194 \\
Uric acid $(\mathrm{mg} / \mathrm{dL})$ & $5.8(1.4)$ & $5.6(1.3)$ & 0.044 \\
$\mathrm{~K}(\mathrm{mmol} / \mathrm{L})$ & $4.1(0.4)$ & $141.0(2.2)$ & 0.005 \\
Na $(\mathrm{mmol} / \mathrm{L})$ & $140.7(2.4)$ & $69.6(16.4)$ & 0.038 \\
eGFR $\left(\mathrm{mL} / \mathrm{min} / 1.73 \mathrm{~m}^{2}\right)$ & $68.8(16.7)$ & $197(33)$ & 0.448 \\
Total cholesterol $(\mathrm{mg} / \mathrm{dL})$ & $197(32)$ & $59(16)$ & 0.828 \\
HDL cholesterol $(\mathrm{mg} / \mathrm{dL})$ & $59(16)$ & $131(71)$ & 0.492 \\
Triglyceride $(\mathrm{mg} / \mathrm{dL})$ & $138(104)$ &
\end{tabular}

Data are mean (SD). $p$ Values indicate statistical difference between groups.

SI conversion factors: To convert total and HDL cholesterol and triglyceride to $\mathrm{mmol} / \mathrm{L}$, multiply values by 0.0259 and 0.0113 , respectively. To convert glucose and uric acid to $\mathrm{mmol} / \mathrm{L}$ and $\mu \mathrm{mol} / \mathrm{L}$, multiply values by 0.0555 and 59.48 , respectively.

$\mathrm{BP}$, blood pressure; eGFR, estimated glomerular filtration rate; HbA1c, glycated haemoglobin; HDL, high-density lipoprotein.

It is of note that almost $80 \%$ of patients in the Diuretic Use group of our study used inhibitors of RAS, while $\beta$-blockers were the main combination drug with diuretics in most studies included in the meta-analysis such as ALLHAT study. ${ }^{5}$ The combination of diuretics and inhibitors of RAS is common in current clinical practice and appears to be associated with a lesser risk of diabetes compared to the combination with a $\beta$-blocker, as shown by the LIFE (Losartan Intervention For End point reduction in hypertension) study. $^{23}$ Therefore, it can be assumed that current therapeutic strategy with diuretics at low doses mostly combined with RAS inhibitors does not carry a high risk for diabetes. However, we could not show clear interactions of concurrent drugs ( $\beta$-blockers and RAS inhibitors) and the risk for diabetes in subgroup analysis, largely because the study was underpowered. Recently, subanalysis of the NAVIGATOR (Nateglinide and Valsartan in Impaired Glucose Tolerance Outcomes Research) study demonstrated that use of diuretics was associated with excess risk for type 2 diabetes. ${ }^{24}$ There is, however, limitation in

Table 4 Incidence of secondary end points

\begin{tabular}{|c|c|c|}
\hline & $\begin{array}{l}\text { Diuretics } \\
\text { group }(n=544)\end{array}$ & $\begin{array}{l}\text { No-diuretics } \\
\text { group }(n=586)\end{array}$ \\
\hline Gout & $6(1.2)$ & $7(1.3)$ \\
\hline $\begin{array}{l}\text { Treatment resistant } \\
\text { hypokalaemia }\end{array}$ & $2(0.4)$ & $1(0.2)$ \\
\hline Stroke & $11(2.2)$ & $5(1.1)$ \\
\hline $\begin{array}{l}\text { Myocardial } \\
\text { infarction }\end{array}$ & $2(0.4)$ & $5(1.0)$ \\
\hline Heart failure & $2(0.4)$ & $6(1.1)$ \\
\hline $\begin{array}{l}\text { Peripheral arterial } \\
\text { disease }\end{array}$ & $2(0.4)$ & $3(0.5)$ \\
\hline Renal dysfunction & $1(0.2)$ & $1(0.2)$ \\
\hline Sudden death & $0(0.0)$ & $1(0.2)$ \\
\hline
\end{tabular}

the interpretation of this result because use of diuretics was not randomised and the doses of diuretics were not as low as our study.

Our study is, as far as we know, the first randomised, controlled trial to assess, as the primary end point, risk in essential hypertensive patients for new onset of diabetes associated with treatment by thiazide diuretics. Most studies showing a higher risk for diabetes from diuretics use were primarily designed to assess cardiovascular events as the primary end point, and new onset of diabetes was assessed by post hoc analysis or, at best, as a prespecified secondary end point.

The mechanisms responsible for the increased incidence of diabetes with use of thiazide diuretics at a high dose have not been fully elucidated. A recent quantitative review showed that thiazide-induced hypokalemia is associated with increased blood glucose. ${ }^{25}$ In the current study, no clinically significant difference in averaged plasma potassium levels were seen during the observation period, which may be attributable to the low dose of diuretics and frequent use of RAS inhibitors, and may partly explain why no difference in the incidence of diabetes between the groups was found.

Serum uric acid levels during the study were significantly higher in the Diuretic group than were those in the No-diuretics group. This may suggest that elevation of uric acid cannot be avoided even by use of low dose with RAS inhibitors. However, the clinical significance of such a small elevation of uric acid is unclear, because treatment with diuretics did not increase the incidence of gout, which is consistent with results from another epidemiological study, in which no significant increase in risk for gout was seen with use of lower doses of diuretics (12.5 mg/day in hydrochlorothiazide equivalents) ${ }^{26}$

\section{Limitation of our study}

As we could not achieve the target sample size, our study is statistically underpowered for the assessment of 
Figure 5 Serum potassium $(A$, ${ }^{*} p=0.007,{ }^{* *} p=0.002,+p=0.020$, $\dagger+p=0.004)$ and uric acid $(B$, ${ }^{*} p<0.0001,{ }^{\star \star} p=0.0004$, $\dagger p=0.0008, \dagger+p=0.002,9 p=0.049$, $\S \mathrm{p}=0.010)$ concentrations over time by treatment groups.
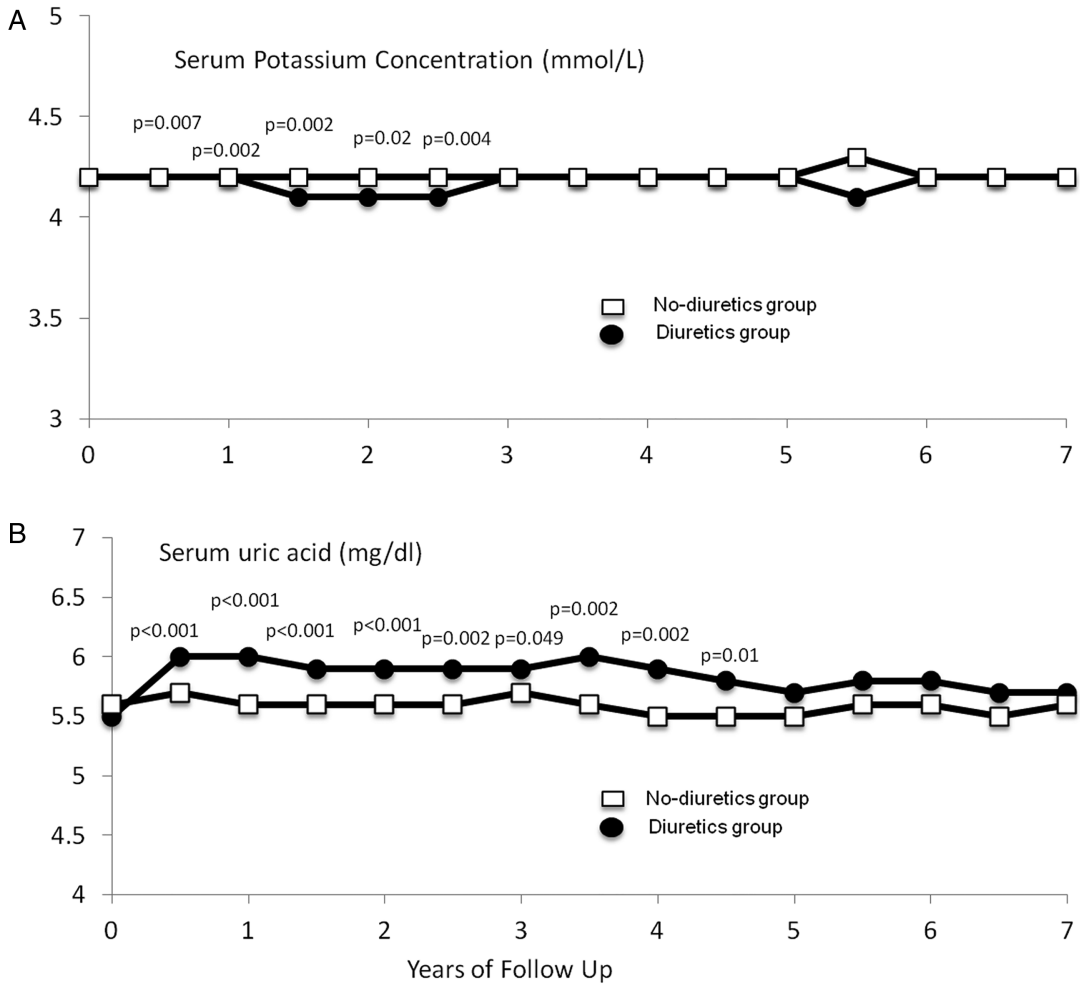

equivalency. Therefore we are able to state that we found no evidence of a difference in outcome, but not that the treatments were equivalent in terms of incidence of diabetes. We conducted a pragmatic trial for the assessment of effectiveness of treatment with low-dose diuretics but not the efficacy of the diuretics per se by using an unblinded study design without any prespecified therapeutic algorithm, which may have impaired internal validity to some extent partly because of clustering of antihypertensives or other drugs such as drugs for hyperuricaemia.

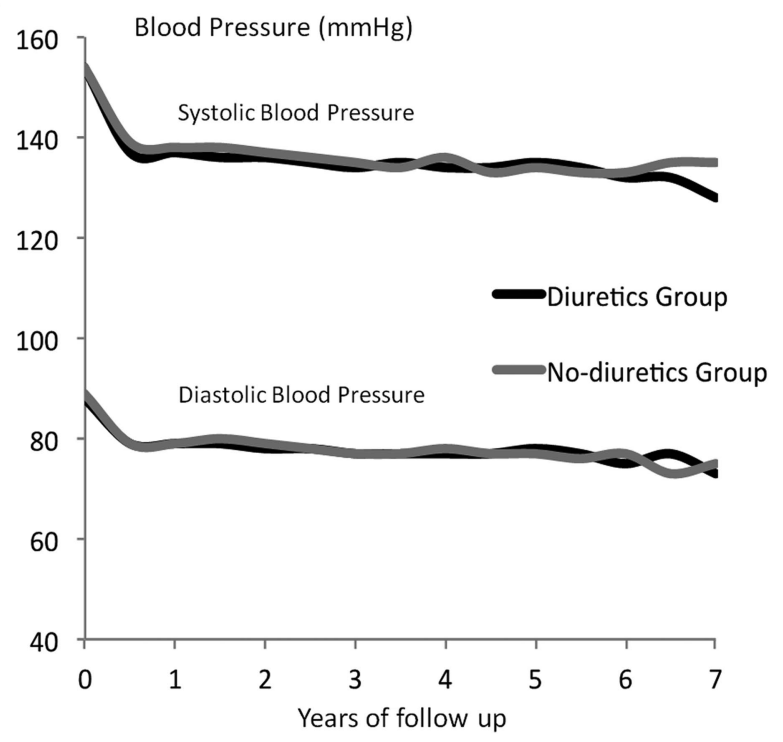

Figure 6 Blood pressure over time by treatment groups.
The ascertainment bias was much less likely even though it was an open study without placebo because we regularly assessed the incidence of diabetes for all patients. However, given that time course of development of type 2 diabetes is uncertain, validity of diagnosis of diabetes in trials such as ours is limited.

\section{Conclusion}

Results from the present randomised controlled trial suggest that current practice of antihypertensive treatment with thiazide diuretics at low doses may not be associated with increased risk for new onset of type 2 diabetes or other clinically significant metabolic abnormalities. These results might suggest safety of use of low doses of thiazide diuretics.

Author affiliations

${ }^{1}$ Department of Clinical Pharmacology \& Therapeutics, University of the Ryukyus, Okinawa, Japan

${ }^{2}$ Department of Internal Medicine, Hyogo Collage of Medicine, Nishinomiya, Japan

${ }^{3}$ Department of Cardiology, Saiseikai-Futsukaichi Hospital, Chikushino, Japan

${ }^{4}$ Sleep Apnea Centre, Kyushu University Hospital, Fukuoka, Japan

${ }^{5}$ Department of Medicine, University of the Ryukyus, Okinawa, Japan

${ }^{6}$ Division of Hypertension and Renal Medicine, National Cardiovascular Research Centre, Suita, Japan

${ }^{7}$ Department of Medicine, Sapporo Medical University, Sapporo, Japan

${ }^{8}$ Department of Geriatric Medicine, Osaka University, Suita, Japan

${ }^{9}$ Department of Medicine, Keio University, Tokyo, Japan

Contributors TM had full access to all of the data in the study and takes responsibility for the integrity of the data and the accuracy of the data analysis. SU, TM, S-iA, S-iT, YK, KS, TO and TS participated in development of the study protocol. SU, TM and S-iA supervised data collection and management. TM conducted the statistical analyses. SU led the writing of the report, which was co-led by TM and assisted by all other authors. While TM 
had full access to all of the study data under the supervision of SU and other authors, SU and other authors could not assess the individual data. All authors assisted in interpretation of the data, and have seen and approved the final version of the report. SU is the guarantor.

Funding This study was supported by the Japan Atherosclerosis Prevention Fund (pilot study) (2002), a grant-in-aid from the Ministry of Health, Labour and Welfare (H15-choju-003, 2003.4-2005.3), the Japanese Society of Hypertension (2005.9-2013.8) and the Osaka Foundation for the Prevention of Cancer and Cardiovascular Diseases, Osaka, Japan (2005.4-2013.8). Bayer, MSD, Pfizer, Dainippon Sumitomo, Shionogi, Astellas, Novartis, Tanabe-Mitsubishi and Takeda Pharmaceuticals also contributed to the funding of this study.

Competing interests SU has received research grants and/or honorariums from Bayer, Pfizer, MSD, Takeda, Tanabe-Mitsubishi, Dai-ichi Sankyo, Dai-nihon-Sumitomo, Astellas, Novartis (Lecturer's fee and Non-purpose Research Grant); Boehringer Ingelheim, Kyowa-Hakko Kirin. TM has received research grants and/or honorariums from Boehringer Ingelheim, Eisai, Kowa, Pfizer, Bayer, Kowa. S-iA has received from research grants and/or honorariums Philips Respironics, Teijin, Astellas, MSD, AstraZeneca, Eisai, Ono, Kissei, Kyowa Hakko Kirin, Shionogi, Dai-ichi Sankyo, Dai-nippon Sumitomo, Toa Eiyo, Novartis, Bayer, Pfizer, Fuji Film, Boehringer Ingelheim, Boston Scientific, ResMed, Mochida, Actelion, Alfresa Corporation, Otsuka, Kowa, Sanofi, Takeda, Fukuda Denshi, Nihon Medi-Physics. S-iT has received honorariums from Astellas, Daiichi-Sankyo, MSD, Novartis, Omron, Tanabe-Mitsubishi, Teijin. YK has received research grants and/or honorariums from MSD, Takeda, Dai-ichi Sankyo, Dai-nippon-Sumitomo, Novartis, Teijin, Omron (Lecturer's fee and Non-purpose Research Grant); Bayer, Pfizer, Tanabe-Mitsubishi, Astellas, Boehringer Ingelheim, Kyowa-Hakko Kirin, Mochida, Sandoz. KS has received honorariums from Takeda, Dai-nippon Sumitomo, Novartis, MSD, Astellas, Dai-ichi Sankyo, Kyowa Hakko Kirin, Kowa, Sanofi, Pfizer, Boehringer Ingelheim, Mochida, Philips Electronics Japan, Teijin, Kissei, Eisai. TO has received honorariums from Takeda, MSD, Dai-ichi Sankyo, Novartis, Kyowa-Hakko Kirin, Boehringer Ingelheim, Shionogi, Pfizer, Bayer, Kotobuki, Astellas, Abbot Japan, Dai-nippon-Sumitomo. TS has received honorariums from Takeda, Pfizer, MSD, Astellas, Dai-ichi Sankyo, Kyowa-Hakko Kirin, Toa Eiyo.

Patient consent Obtained.

Ethics approval The study was conducted in accord with the Declaration of Helsinki and the ethics guidelines for clinical research from the Ministry of Health, Labour and Welfare, Japan. The protocol and all subsequent amendments to the protocol were reviewed and accepted by the ethics committees of the University of the Ryukyus, as the central ethics committee, and by each site where this study was conducted.

Provenance and peer review Not commissioned; externally peer reviewed.

Data sharing statement No additional data are available.

Open Access This is an Open Access article distributed in accordance with the Creative Commons Attribution Non Commercial (CC BY-NC 3.0) license, which permits others to distribute, remix, adapt, build upon this work noncommercially, and license their derivative works on different terms, provided the original work is properly cited and the use is non-commercial. See: http:// creativecommons.org/licenses/by-nc/3.0/

\section{REFERENCES}

1. Psaty BM, Smith NL, Siscovick DS, et al. Health outcomes associated with antihypertensive therapies used as first-line agents: a systematic review and meta analysis. JAMA 1997;277:739-45.

2. Medical Research Council Working Party. Medical Research Council trial of treatment of hypertension in older adults: principal results. BMJ 1992;304:405-12.

3. SHEP Cooperative Research Group. Prevention of stroke by antihypertensive drug treatment in older persons with isolated systolic hypertension: final results of the Systolic Hypertension in the Elderly Program (SHEP). JAMA 1991;265:3255-64.
4. Medical Research Council Working Party. MRC trial of treatment of mild hypertension: principal results. Br Med J (Clin Res Ed) 1985;291:97-104.

5. ALLHAT Officers and Coordinators for the ALLHAT Collaborative Research Group. The Antihypertensive and Lipid-Lowering Treatment to Prevent Heart Attack Trial. Major outcomes in high risk hypertensive patients randomized to angiotensin-converting enzyme inhibitor or calcium channel blocker vs. diuretic: the Antihypertensive and Lipid-Lowering Treatment to Prevent Heart Attack Trial (ALLHAT). JAMA 2002;288:2981-97.

6. Grossman E, Verdecchia P, Shamiss A, et al. Diuretic treatment of hypertension. Diabetes Care 2011;34(Suppl 2):S313-19.

7. Sarafidis P, Bakris GL. Antihypertensive therapy and the risk of new-onset diabetes. Diabetes Care 2006;29:1167-9.

8. Taylor EN, Hu FB, Curhan GC. Antihypertensive medications and the risk of incident type 2 diabetes. Diabetes Care 2006;29:1065-70.

9. Elliott WJ, Meyer PM. Incident diabetes in clinical trials of antihypertensive drugs: a network meta-analysis. Lancet 2007;369:201-7.

10. Pocock SJ. Clinical trials: a practical approach. John Wiley, 1983.

11. Treasure T, MacRae KD. Minimisation: the platinum standard for trials? Randomisation doesn't guarantee similarity of groups; minimisation does. BMJ 1998;317:362-3.

12. Definition, diagnosis and classification of diabetes mellitus and its complications. Part 1: diagnosis and classification of diabetes mellitus. Geneva: World Health Organization, 1999 (WHO/NCD/NCS/99.2).

13. http://www.jds.or.jp/modules/study/index.php?content_id=10\#english

14. Wallace SL, Robinson H, Masi AT, et al. Preliminary criteria for the classification of the acute arthritis of primary gout. Arthritis Rheum 1977;20:895-900.

15. Thorvaldsen $\mathrm{P}$, Kuulasmaa K, Rajakangas $\mathrm{AM}$, et al. Stroke trends in the WHO MONICA project. Stroke 1997;28:500-6.

16. Luepker RV, Apple FS, Christenson RH, et al. AHA Council on Epidemiology and Prevention; AHA Statistics Committee; World Heart Federation Council on Epidemiology and Prevention; European Society of Cardiology Working Group on Epidemiology and Prevention; Centers for Disease Control and Prevention; National Heart, Lung, and Blood Institute: Case Definitions for Acute Coronary Heart Disease in Epidemiology and Clinical Research Studies. a statement from the AHA Council on Epidemiology and Prevention; AHA Statistics Committee; World Heart Federation Council on Epidemiology and Prevention; the European Society of Cardiology Working Group on Epidemiology and Prevention; Centers for Disease Control and Prevention; and the National Heart, Lung, and Blood Institute. Circulation 2003;108:2543-9.

17. McKee PA, Castelli WP, McNamara PM, et al. The natural history of congestive heart failure: the Framingham study. $N$ Engl J Med 1971;285:1441-6.

18. Fontaine R, Kim M, Kieny R. Die chirurgische Behandlung der peripheren Durch-bluntungsstorungen. Helv Chir Acta 1954; 5/6:499-533.

19. Curb JD, Pressel SL, Cutler JA, et al. Effect of diuretic-based antihypertensive treatment on cardiovascular disease risk in older diabetic patients with isolated systolic hypertension. JAMA 1996;276:1886-92

20. Brown MJ, Palmer CR, Castaigne A, et al. Morbidity and mortality in patients randomized to double-blind treatment with a long-acting calcium channel blocker or diuretic in the International Nifedipine GITS study: intervention as a goal in hypertension treatment (INSIGHT). Lancet 2000;356:366-72.

21. Bakris G, Molitch M, Hewkin A, et al. Differences in glucose tolerance between fixed-dose antihypertensive drug combinations in people with metabolic syndrome. Diabetes Care 2006;29:2592-7.

22. Carlsen JE, Køber L, Torp-Pedersen C, et al. Relation between dose of bendrofluazide, antihypertensive effect, and adverse biochemical effects. BMJ 1990;300:975-8.

23. Dahlöf B, Devereux RB, Kjeldsen SE, et al. LIFE Study Group: cardiovascular morbidity and mortality in the Losartan Intervention For Endpoint reduction in hypertension study (LIFE): a randomised trial against atenolol. Lancet 2002;359:995-1003.

24. Shen L, Shah BR, Reyes EM, et al. Role of diuretics, $\beta$ blockers, and statins in increasing the risk of diabetes in patients with impaired glucose tolerance: reanalysis of data from the NAVIGATOR study. BMJ 2013;347:f6745.

25. Zillich AJ, Garg J, Basu S, et al. Thiazide diuretics, potassium, and the development of diabetes: a quantitative review. Hypertension 2006;48:219-24.

26. Gurwitz JH, Kalish SC, Bohn RL, et al. Thiazide diuretics and the initiation of anti-gout therapy. J Clin Epidemiol 1997;50:953-9. 